\title{
0354. Effects of sodium nitroprusside in addition to therapeutic hypothermia after experimental cardiac arrest
}

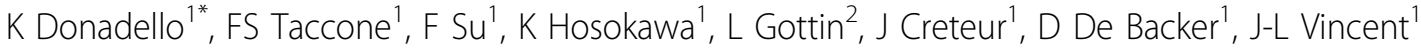 \\ From ESICM LIVES 2014 \\ Barcelona, Spain. 27 September - 1 October 2014
}

\section{Introduction}

Sodium nitroprusside (SNP) has been shown to provide additional protective effects when combined with therapeutic hypothermia $(\mathrm{TH})$ in some experimental models of cardiac arrest (CA) $[1,2,3]$.

\section{Objectives}

To determine whether the addition of SNP to TH has beneficial effects on the brain in a porcine model of CA.

\section{Methods}

We studied 8 anesthetized, invasively monitored and mechanically ventilated domestic pigs, randomized into two groups $(\mathrm{n}=4)$ : TH without or with SNP. After $3 \mathrm{~min}$ of untreated ventricular fibrillation, cardiopulmonary resuscitation (CPR) was started in all animals and continued until return of spontaneous circulation (ROSC); defibrillation was performed 3 minutes after the start of CPR. Hypothermia $\left(34 \pm 1^{\circ} \mathrm{C}\right)$ was induced at the start of CPR using a rapid IV infusion of $30 \mathrm{~mL} / \mathrm{kg}$ cold saline for 60 min, trans-nasal evaporative cooling (Rhinochill, Benechill Inc, USA) and surface cooling with ice packs. Cooling was maintained for 6 hours, followed by controlled slow rewarming to baseline temperature with blankets. SNP $+\mathrm{TH}$ animals received 3 bolus injections of $1 \mathrm{mg}$ of SNP after 2, 7 and 12 minutes of CPR. Brain temperature was measured with intraparenchymal probes (Licox CC1.SB, Integra, NeuroSciences Ltd., Hampshire, UK), blood brain flow by laser Doppler (blood laser Doppler [BLD], MNP100XP, Oxyflow, Oxford Optronix, Oxford, UK) and the lactate-pyruvate ratio (LPR) was measured hourly by microdialysis (CMA20, CMA, Sweden). After left craniectomy, the microvascular network of the frontal cortex was evaluated using sidestream dark-field videomicroscopy (Microscan, MicroVision Medical, Netherlands) at baseline (T0), 1 hour after cooling induction (T1), at the end of hypothermia (T2) and after rewarming (T3). The mean flow index (MFI) and the proportion of perfused cerebral

Table 1

\begin{tabular}{lllllllll}
\hline Time & T0 & T0 & T1 & T1 & T2 & T2 & T3 & T3 \\
\hline Study Group & TH & TH-SNP & TH & TH-SNP & TH & TH-SNP & TH & TH-SNP \\
\hline Heart rate, bpm & $73.7 \pm 9.3$ & $73.5 \pm 11.5$ & $86.5 \pm 7.6$ & $89.5 \pm 7.4$ & $55.8 \pm 11.8$ & $55.5 \pm 6.4$ & $83.3 \pm 9.8$ & $80.6 \pm 4.3$ \\
\hline Mean arterial pressure, $\mathrm{mmHg}$ & $113.3 \pm 8.4$ & $112.0 \pm 5.4$ & $103.3 \pm 8.6$ & $94.5 \pm 8.4$ & $86.8 \pm 18.1$ & $79.0 \pm 9.4$ & $82.8 \pm 10.3$ & $90.3 \pm 3.9$ \\
\hline PPV, \% & $86.8 \pm 3.4$ & $86.5 \pm 2.7$ & $39.5 \pm 12.6 \$$ & $45.3 \pm 6.3 \$$ & $39.6 \pm 14.2 \$$ & $49.8 \pm 13.2 \$$ & $56.3 \pm 6.8 \$$ & $65.5 \pm 6.7 \$$ \\
\hline MFI & $2.8 \pm 0.1$ & $2.8 \pm 0.1$ & $1.9 \pm 0.1 \$$ & $2.0 \pm 0.1 \$$ & $1.7 \pm 0.1 \$$ & $1.9 \pm 0.2 \$$ & $2.3 \pm 0.2 \$$ & $2.7 \pm 0.1 * \$$ \\
\hline BLD (\%/baseline) & 100 & 100 & $42.1 \pm 1.9 \$$ & $51.3 \pm 3.5 \$$ & $52.8 \pm 2.9 \$$ & $53.6 \pm 2.5 \$$ & $90.7 \pm 0.6 \$$ & $92.5 \pm 2.1 \$$ \\
\hline LPR & $12.5 \pm 1.8$ & $13.9 \pm 4.1$ & $16.3 \pm 4.1$ & $19.7 \pm 1.7$ & $31.7 \pm 5.4 \$$ & $24.3 \pm 3.3 \$$ & $61.1 \pm 13.8 \$$ & $40.5 \pm 1.3 * \$$ \\
\hline
\end{tabular}

$\left(^{*}=p<0.05\right.$ versus TH-SNP; ${ }^{5}=p<0.05$ versus TO $)$.

${ }^{1}$ Erasme University Hospital, Intensive Care Department, Brussels, Belgium

Full list of author information is available at the end of the article 
small vessels (PPV) were calculated using standard formulas.

\section{Results}

Time to return of spontaneous circulation was similar in both groups (8 [7-23] $\mathrm{min}$ for $\mathrm{TH}$ alone and 9 [6-22] $\mathrm{min}$ for $\mathrm{TH}+\mathrm{SNP})$. Despite its known vasodilatory effects, there were no significant differences in measured hemodynamic parameters between the groups throughout the study period. Microvascular perfusion was significantly reduced after $\mathrm{CA}$ in both groups, but to a lesser extent in the TH-SNP than in the TH group. The LPR was lower in the TH-SNP than in the TH group (Result Table 1).

\section{Conclusions}

In this model, the cerebral microcirculation was significantly altered after CA; addition of SNP to TH attenuated the microvascular alterations and had a protective effect on brain metabolism.

\section{Grant acknowledgment}

Fonds Erasme. Bourse de Recherche 2013-2014.

\section{Authors' details}

${ }^{1}$ Erasme University Hospital, Intensive Care Department, Brussels, Belgium.

${ }^{2}$ University of Verone, School of Medicine, Policlinico G.B. Rossi, Intensive

Care Department, Verone, Italy.

Published: 26 September 2014

\section{References}

1. Donadello K, et al: CCM 2012, 40(12 suppl):545.

2. Schultz J, et al: Resuscitation 2012, 83:374-377.

3. Yannopoulos D, et al: Resuscitation 2013, 84(8):1143-9.

doi:10.1186/2197-425X-2-S1-P20

Cite this article as: Donadello et al:: 0354. Effects of sodium nitroprusside in addition to therapeutic hypothermia after experimental cardiac arrest. Intensive Care Medicine Experimental 2014 2(Suppl 1):P20.

\section{Submit your manuscript to a SpringerOpen ${ }^{\mathcal{D}}$ journal and benefit from:}

- Convenient online submission

- Rigorous peer review

- Immediate publication on acceptance

- Open access: articles freely available online

- High visibility within the field

- Retaining the copyright to your article

Submit your next manuscript at $>$ springeropen.com 